DOI 10.37882/2500-3682.2021.08.22

\title{
ФАКТОРЫ, КОТОРЫЕ ОКАЗЫВАЮТ ВЛИЯНИЕ НА ФОРМИРОВАНИЕ ЦЕННОСТНЫХ ОРИЕНТАЦИЙ В ПОДРОСТКОВОМ ВОЗРАСТЕ
}

\section{FACTORS THAT INFLUENCE THE FORMATION OF VALUE ORIENTATIONS IN ADOLESCENCE}

\section{A. Fomina}

Summary: In this study, an attempt was made to establish the factors that influence the process of forming value orientations of an individual. The most interesting to the author is adolescence, when a stable circle of interests is formed, which is the basis of the value orientations of adolescents. The author notes that the upbringing of children in modern Russian society is carried out in the conditions of economic and political reform, during which the situation of the younger generation, the principles of functioning of educational institutions, youth associations and the mass media have significantly changed. Among the factors of influence, the author highlights such as: family, social environment and school.

Keywords: social environment; value orientations; adolescence; family, educational process, factors.

\author{
Фомина Александра Павловна \\ ГОУ ВО МО «Государственный гуманитарно- \\ технологический университет» \\ sacha-fomina@yandex.ru
}

Аннотация: В этом исследовании была сделана попытка установить факторы, которые оказывают влияние на процесс формирования ценностных ориентаций личности. Наиболее интересным автору представляется подростковый возраст, когда формируется устойчивый круг интересов, являющийся базой ценностных ориентаций подростков. Автор отмечает, что воспитание детей в современном российском обществе осуществляется в условиях экономического и политического реформирования, в ходе которого существенно изменились положение подрастающего поколения, принципы функционирования образовательных учреждений, молодёжных объединений и средств массовой информации. Среди факторов влияния автор особо выделяет такие как: семья, социальное окружение и школа.

Ключевые слова: социальное окружение; ценностные ориентации; подростковый возраст; семья, учебный процесс, факторы.

димо рассматривать в качестве ведущей социальной деятельности, которая напрямую связана с процессом формирования норм, ценностей и идеалов [3]. В связи с тем, что человеку характерно ценностное восприятие окружающего мира, необходимо с самого детства заниматься формированием его системы ценностей. Крайне важным этот процесс является для детей в подростковом возрасте (с 10-11 до 15-16 лет). Дети в подростковом возрасте наиболее предрасположены к формированию духовных, эмоциональных и нравственных ориентиров. То, что человек запоминает в подростковом возрасте, характеризуется высокими показателями психологической устойчивости.

Ценностные ориентации - это крайне непростой социальный и психологический феномен, который характеризует целостный подход личности к окружающему миру, отношение к себе, задает направление поведения и значение всем действиям человека [2]. В научных работах Артюховой Ю.В. отмечается, что термин «ценностные ориентации» начали использовать в послевоенное время в области социальной психологии в качестве аналога термина «понятие ценностей» из философии, однако и в настоящее время нет точного разделения этих двух понятий.

С позиции педагогики ценностные ориентации необ- 
ходимо рассматривать в качестве осознанного выбора человека, а также как соотношение базовых социальных ценностей с системой ценностей личности. Это требуется для гармоничного сосуществования как с самим собой, так и с миром. Для того чтобы реализовать данную задачу, необходимо получить ответ на вопрос о том, какие именно факторы оказывают воздействие на процесс формирования системы ценностей у современных детей в подростковом возрасте.

Каждый фактор может оказывать как негативное, так и позитивное влияние.

В рамках данной работы были выделены внешние и внутренние факторы.

К числу внутренних факторов относятся: волевые характеристики человека, виды высшей нервной деятельности, эмоциональные реакции, а также показатели уровня интеллектуального развития.

Отдельно необходимо отметить волевые характеристики человека. Степень их развития определяет активность в подростковом возрасте, которая нацелена на процесс выработки персональной ценностной ориентации [8]. Степень интеллектуальных навыков несет ответственность за процесс формирования разных понятий, которые необходимы для рационального оценивания различных проявлений, основанных на идеалах и нормах. Эмоциональные реакции личности - это требуемое условие для того, чтобы осуществлять внутреннее осознание и принятие осмысленных норм общества.

На процесс формирования системы ценностей в подростковом возрасте также оказывают влияние различные факторы извне. К ним можно причислить: средства массовой информации, семью, родственников и близкое окружение, а также образовательные учреждения и разные проявления современной массовой культуры. Естественно, процесс становления системы ценностей начинается в семье, ведь тут подросток проходит процесс социализации и формирует базовые правила и нормы поведения в социуме, изучает реакции близких на разные обстоятельства. Стоит понимать, что система ценностей подростка напрямую зависит от родителей, ведь подростки ориентируются на то, как семья оценивает происходящие поступки и ситуации, формируя на их основе свои нравственные ориентации. Подростки копируют взаимоотношения внутри семьи, следуют доминирующим системам ценностей в семье, ориентируются на них, долгое время используют принятые в семье реакции на происходящее вокруг. В случае если семья не выступает для подростка в качестве авторитета, то их слова не смогут влиять на него, ведь он просто не будет их воспринимать. Помимо семьи, дети в подростковом возрасте поддаются воздействию ближайшего окружения, т.н. влияние «улицы». Для старшеклассников характерно значительное влияние сверстников. В такой ситуации ослабевают правила и нормы, которые были привиты в семье. Следовательно, возникает принципиально новый фактор воздействия, влияющий на процесс становления системы ценностей. В подростковом возрасте дети чаще всего пытаются добиться признания от ближайшего окружения. Подросток пытается проводить больше времени с друзьями, воспринимая от них как хорошее, так и плохое. В стремлении сохранить свой круг общения он пытается подстроиться под стандарты определенной социальной группы, таким образом он принимает новые ориентации в свою систему ценностей. Чаще всего в качестве лидеров подобных социальных групп выступают наглые люди, которые пренебрежительно относятся к нормам нравственного поведения. В стремлении получить одобрение лидера такой группы подросток копирует его убеждения, взгляды и стандарты поведения. Огромное значение в процессе формирования системы ценностей играют молодежные субкультуры, которые помогают подросткам приспособиться к миру, принять новые роли в социуме. Стоит отметить, что от типа субкультуры напрямую зависит то, какую именно систему ценностей сформирует ребенок. Ориентации в просоциальных субкультурах не противопоставляются социальным, а дополняют их. Однако в антисоциальных субкультурах ценности напрямую противоречат социальным. В асоциальных субкультурах существуют как социальные, так и антисоциальные направленности [7]. В качестве еще одного значимого внешнего фактора воздействия, который может играть как положительную, так и отрицательную роль в процессе формирования системы ценностей, выступают СМИ. Детальнее рассмотрим воздействие Интернета и телевидения, ведь они сейчас являются очень популярными. По критерию воспитательного воздействия телевидение должно занимать одно из главных мест. Одной из основных проблем на телевидении выступает насилие. Сейчас почти во всех фильмах, сериалах, а иногда даже и в мультфильмах присутствуют те или иные проявления насилия в определенных формах. Насилие в фильмах всегда выглядит эффектно, поэтому его принято воспринимать в качестве нормы. На этом фоне может сформироваться неправильная система ценностей. Транслируя подобные сцены, телевидение крайне негативно воздействует на процессы развития творческих навыков и мышление подростков. Однако телевидение нельзя полностью исключать полностью из жизни подростков. При этом необходимо объяснять детям, что насилие на экране и в жизни во многом отличается. Необходимо осуждать агрессивные действия на экране. Однако следует отметить и положительное воздействие телевидения, которое может влиять на процесс формирования системы ценности подростков. К примеру, телевидение выполняет функции информирования населения, может значительно повысить уровень культуры молодых лю- 
дей. Также в настоящее время крайне популярным стал Интернет. Стоит отметить негативное воздействие Сети, В которой нередко можно встретить сомнительную или откровенно неправдивую информацию. Информация о влиянии наркотических веществ, а также суицидах может сформировать увлечение молодых людей подобными вещами. В связи с доступностью Интернета дети в подростковом возрасте могут увлечься различными сектами, радикальными политическими взглядами или азартными играми. В наши дни Интернет и телевидение играют решающую роль в процессе формирования системы ценностей после семьи и выступают доминирующим фактором, который влияет на подростков.

С возрастом подростки все меньше подвержены влиянию семьи, при этом значительно усиливается отрицательное воздействие Интернета. В таких условиях школа становится одним из воспитательных факторов. В учебном заведении дети контактируют с ровесниками и педагогами примерно по шесть часов в день. Естественно, это напрямую влияет на жизнь подростка, стандарты его поведения и систему ценностей. В школе дети получают не просто знания, но также духовное и нравственное воспитание [5]. В работах Панковой Т.А. отмечается, что в ходе воспитания и обучения в школе подростки формируют свое мировоззрение и убеждения, систему общественных установок, а также ценности, которые определяют их отношение к социуму и миру, другим людям и к себе [9]. В условиях современного учебного процесса ценностные ориентации выступают в качестве объекта деятельности педагога и учеников, их семьи, а также сотрудников внешкольных заведений. В ходе формирования ценностных ориентаций в качестве приоритетной педагогической цели выступает донесение ценностных ориентаций до сознания ученика. Данный процесс крайне непростой и состоит из таких стадий:

1. Демонстрация ценностей.

2. Ценностно-ориентированная деятельность, в ходе которой подросток осознает важность определенных норм для себя, а также принимает их.

3. Применение системы ценностей в повседневной жизни.

Учитель может влиять на формирование системы ценностей учащихся при помощи:

- формирования ситуаций ценностного выбора;

- ценностного диалога;

- личностного воздействия;

- специального формирования ценностных ситуаций с целью принятия их учениками;

- погружения в среду ценностей.

Ценности подростка могут формироваться в семье, различных неформальных объединениях, под воздействием СМИ. Однако самым важным и последовательным влиянием на воспитание в подростках системы нравственных ориентаций выступает школа, которая занимает огромное место в их жизни, ведь они проводят в школе множество времени. Можно согласиться с мнением Щурковой Н.Е., которая утверждала, что в качестве одной из самых важных задач в школьном образовании выступает содействие и помощь ученикам в формировании собственной устойчивой и непротиворечивой системы ценностей, которая будет гарантировать гармоничное взаимодействие подростка с самим собой и с миром [11, с.28-29].

\section{ЛИТЕРАТУРА}

1. Акбаров, Н.Г. Социальные процессы трансформирующегося общества: проблема подростка - проблема страны / Н.Г. Акбаров. - Научные труды, 2001. - 92

2. Артюхова И. Ценности - цели подрастающего поколения: На первом месте - здоровье, а творчество на последнем // Директор школы. - 2001. - №10. C.84-87.

3. Асмолов А.Г. Личность как предмет психологического исследования -«Издательство МГУ» - 2005.- С.95

4. Гаврилюк В.В., Трикоз Н.А. Динамика ценностных ориентаций в период социальной трансформации (поколенный подход) // Социол. исслед. - 2002. №1. - C.96-105.

5. Дырин СП., Чичаева И.И. Ценности образования в современном российском общественном сознании./ Под ред. СП. Дырина. Набережные Челны, 2001. - 256 стр.

6. Жиров Ю.С. Семья в системе ценностей учащейся молодежи // Социальна-педагогічная робота. - 2004. - № 6. - 139 с.

7. Журавлева, Н.А. Динамика ценностных ориентаций личности в российском обществе/Н.А. Журавлева. - М.: Институт психологии РАН, 2006.-335 с.

8. Мамедова Ж.С. Ценностные ориентации личности в контексте временной перспективы. // Гуманитарные и социально-экономические науки. Спецвыпуск «Педагогика» № 6. Ростов-на-Дону, издательство РГПУ, 2006. С. 121 - 132 (статья).

9. Панкова Т.А. 0 становлении нравственных и гражданских позиций школьников // Социол. исслед. - 2002. - №5. - С.111-114.

10. Шерковин Ю.А. Проблема ценностных ориентации и массовые информационные процессы // Психологический журнал. 1982. Т. 3. №5. - с. 135-145.

11. Щуркова Н.Е. Классное руководство: теория, методика, технология. - М.: Педагогическое общество России, 2000. - 256 с.

(с) Фомина Александра Павловна (sacha-fomina@yandex.ru).

Журнал «Современная наука: актуальные проблемы теории и практики» 